\title{
Nurses Opinions Regarding Delirium Care in the Older General Hospital Population and in Older Cardiac Surgery Patients Specifically: A Multicentre Survey among Dutch Nurses
}

\author{
Roelof Ettema1,2*, Dianne van Harten ${ }^{3}$, Jita Hoogerduijn'1, Tjitze Hoekstra4, \\ Marieke Schuurmans ${ }^{1,2}$ \\ ${ }^{1}$ Nursing and Paramedical Care for People with Chronic Illnesses, Faculty of Health Care, University of Applied \\ Science Utrecht, Utrecht, The Netherlands \\ ${ }^{2}$ Julius Center for Health Sciences and Primary Care, University Medical Center Utrecht, Utrecht, The \\ Netherlands \\ ${ }^{3}$ Department of Surgery and Orthopedics, Röpcke Zweers Hospital, Hardenberg, The Netherlands \\ ${ }^{4}$ Heart and Lung Department, St. Antonius Hospital, Nieuwegein, The Netherlands \\ Email: ${ }^{*}$ Roelof.Ettema@hu.nl
}

Received 22 October 2014; revised 23 November 2014; accepted 10 December 2014

Copyright (C) 2014 by authors and Scientific Research Publishing Inc.

This work is licensed under the Creative Commons Attribution International License (CC BY).

http://creativecommons.org/licenses/by/4.0/

(c) (i) Open Access

\section{Abstract}

Background: Delirium is a high prevalent postoperative complication in older cardiac surgery patients and can have drastic consequence for the patient. Preventive interventions, diagnosis and treatment of delirium require specialized knowledge and skills. Objective: To gain insight in the current opinion and beliefs of nurses in hospitals concerning prevention, diagnosis and treatment of delirium in older hospital patients in general and specifically in older cardiac surgery patients. Methods: In a cross-sectional study from February to July 2010, we distributed a survey on beliefs on delirium care among 368 nurses in three hospitals in the Netherlands, in one hospital in all wards with older patients and in two hospitals in the cardiac surgery wards only. Results: Although in literature incidence rates up to $54.9 \%$ in cardiac surgery patients in hospitals are reported, with a response rate of $68 \%(250)$, half of the nurses believe that the incidence of delirium is not even $10 \%$. Two thirds think that delirium in patients is preventable. Although, the Delirium Observation Scale is most often used for screening delirium, nearly all nurses do not routinely screen patients for delirium. Opinions on delirium of nurses working in cardiac surgery wards did not differ from nurses caring for older patients in other hospital wards. Conclusions: Nurses do

${ }^{*}$ Corresponding author.

How to cite this paper: Ettema, R., et al. (2014) Nurses Opinions Regarding Delirium Care in the Older General Hospital Population and in Older Cardiac Surgery Patients Specifically: A Multicentre Survey among Dutch Nurses. International Journal of Clinical Medicine, 5, 1352-1364. http://dx.doi.org/10.4236/ijcm.2014.521173 
have knowledge on delirium care, but there is a gap between the reported incidence in literature and the estimation of the occurrence of delirium by nurses. A two-way causal relationship emerges: because nurses underestimate the occurrence, they do not screen patients on a routine basis. And because they do not screen patients on a routine basis they underestimate the incidence.

\section{Keywords}

\section{Frailty, Older People, General Hospital, Cardiac Surgery, Delirium}

\section{Introduction}

In the past decades, mortality during or shortly after cardiac surgery has decreased [1]. However, morbidity has increased [2], mainly because cardiac surgery is increasingly utilized in older and more vulnerable patients. This often results in more complications after surgery and potential reduction in quality of life [3]-[5]. One high prevalent postoperative complication in older cardiac surgery patients is delirium, with reported incidences of $8 \%$ to $31 \%$ in isolated coronary artery bypass grafting (CABG) [6] [7] and $14.7 \%$ to $54.9 \%$ in all cardiac surgeries [8]-[13].

In the Diagnostic and Statistical Manual of Mental Disorders-IV-TR a delirium is defined as a syndrome of many different causes characterized by confusion and loss of short-term memory [14]. More specifically, a delirium in the elderly patients is a transient, mostly reversible organic-mental syndrome with acute confusion, cognitive impairment, decline of vigilance, increased or reduced psychomotor activity and a disturbed sleepwake-cycle [15]. The etiology of delirium is multifactorial [15]. Patients with delirium present with combinations of cognitive failure, fluctuating levels of consciousness, changes in the sleep-wake cycle, and variable severity of psychomotor agitation, hallucinations, delusions and other perception abnormalities [16]. Delirium is associated with functional decline at one month in cardiac surgery patients [11], with postoperative cognitive dysfunction at one week post-surgery in CABG patients [17] and with sleep disturbances in cardiac surgery patients [10]. Subsequently, delirium is associated with an increased risk on admission in a hospital or nursing home [18].

An occurring delirium can have drastic long term consequences for the patient, like prolonged (months) functional (activity of daily live) dependency, an enormous fear because of occurring hallucinations, increased morbidity and mortality [18] [19]. Consequently, a delirium increases patient burden, healthcare demand and healthcare costs.

Preventive interventions, diagnosis and treatment of delirium require specialized knowledge and skills. Since nurses play a key role in hospital care, a successful implementation of nursing interventions for prevention, early and accurate diagnosis and treatment of delirium in older surgery patients is important. A survey conducted in 2005 in the University Hospitals of Leuven in Belgium demonstrated that the incidence of delirium and its association with an increased morbidity and mortality was underestimated by nurses and physicians in the older general hospital population [20]. Results of a survey on quality of delirium care under twenty Dutch hospitals executed by the Dutch Health Care Inspectorate [21], revealed that there was no policy in the hospitals and nurses and physicians have insufficient knowledge on prevention, diagnoses and treatment of delirium.

Much research is done on delirium care focussing on causes in patients. However, in literature the reported incidence rates of delirium in cardiac surgery patients in hospitals still keep increasing with the increasing age of patients going for cardiac surgery and still little is known about nurses' opinions regarding delirium or how they manage delirium in cardiac surgery patients. Therefore, the aim of our study is to understand the current opinion and beliefs of nurses in hospitals about prevention, diagnosis and treatment of delirium in older hospital patients in general and specifically in older cardiac surgery patients.

\section{Methods}

In a cross-sectional survey from February to July 2010, we distributed questionnaires on beliefs on delirium care among 368 nurses in three hospitals in the Netherlands. The ethical review boards of the three involved hospitals gave approval for the study. 


\subsection{Development of the Questionnaire}

The questionnaire used for this survey was originally developed by a panel of delirium experts from Vanderbilt University Medical Centre including the disciplines of nursing, critical care medicine, clinical psychology, and geriatric neuropsychology, through a deliberate step-wise process that included item generation and construction and pilot testing and clarification for the use in intensive care [22]. Subsequently, the questionnaire was translated into the Flemish Dutch language and adjusted to be applicable in all clinical departments in the hospital. This was done by a panel of Flemish experts working in the university hospitals of Leuven in Belgium and tested on face validity [20].

For this study the Flemish Dutch questionnaire was adjusted into the general Dutch language, particularly to be applicable in the nursing population, by the University of Utrecht and the University of Applied Science Utrecht. Because Flemish and Dutch are very similar languages, Flemish nurses working in geriatric and psychiatric care checked the interpretation. Furthermore, the questionnaire was face validity tested by a psychiatric nurse and a psychiatrist, both involved in delirium care in the Röpcke Zweers hospital in the Netherlands. Finally the University of Applied Science Utrecht did a pilot test of the questionnaire in the St. Antonius hospital in Nieuwegein, which resulted in a confirmation of the questionnaire. Both the face validity test and pilot test did not lead to adjustments of the questionnaire.

\subsection{Design of the Questionnaire}

The questionnaire was designed into two parts. In the first part the nurse was asked for demographic data like age, gender, education, years of experience and main practice setting in the hospital. In the second part, the nurse was asked for the opinion on the prevention, prevalence, severity, detection and diagnosis, and treatment of delirium of patients in the ward. Because the highest incidence of delirium is occurring in patients above 70 years of age, in the questionnaire a distinction is made between opinions of nurses on the prognosis of delirium in patients of 70 years and younger and patients above 70 [22] [24]. The questionnaire is presented in the Appendix.

\subsection{Population and Data Collection}

The first of the three centres was the Röpcke Zweers local hospital in Hardenberg, which is located in the eastern part of the Netherlands; the second centre was the St. Antonius hospital in Nieuwegein; the third centre was the University Medical Centre Utrecht. Both the second and third centres are also specialized in cardiac and thoracic surgery and are located in the central part of the Netherlands. In the first centre the questionnaire was distributed among all nurses who were involved in care to adult surgery and non-surgery patients. In both the second and the third centre the survey was distributed among all nurses working in the cardiothoracic surgery department.

Nurses included in the survey received the questionnaire. This questionnaire was accompanied by an introduction letter, including information on the purpose of study, anonymous treatment of the information the respondent provided and an invitation to cooperate. By returning the completed questionnaire the responding nurse gave implied consent to use their provided information for this study.

\subsection{Data Analysis}

The estimates of the respondents concerning: 1) the Incidence and Prevalence of Delirium, 2) Diagnosis of Delirium, 3) Outcomes of Delirium and 4) Treatment of Delirium, where calculated in percentages. For respondents' estimate concerning risk factors for Delirium the mean of the result of the five point Likert scales was calculated. The different estimated importance of the outcome of the Delirium for the patients younger than 70 years and patients of 70 years and older was tested for each centre using the chi square test. Chi-square and Fisher's exact tests were used to analyse categorical values where appropriate, and Student's t-test was used to analyse continuous variables which were normally distributed. Two-sided statistical testing was conducted with a level of significance of 0.05. The statistical package R (version 2.14.2 (2012-02-29), The R Foundation for Statistical Computing) was used for statistical calculations. The package Microsoft Excel (version 14.0.6112.5000 (2010), Microsoft Corporation) was used to construct the figures. 


\section{Results}

Out of 368 nurses who received the invitation, a total of 250 questionnaires were completed resulting in a response rate of $68 \%$. The response rate per hospital and the demographics of the responding nurses are presented in Table 1. Half of the respondents were 30 years or younger and one third 40 year or older. As expected, the majority was female. Nearly $60 \%$ had completed an intermediate vocational training and over $40 \%$ had a bachelor degree in nursing. Over $60 \%$ worked four of five days per week and above $70 \%$ had four or more years of experience in nursing.

The questionnaires were completed by nurses from different practice settings as presented in Figure 1 . In the St. Antonius Hospital (centre 2) and the University Medical Hospital (centre 3) the questionnaires were deliberately distributed among nurses working at cardiothoracic surgery department only. In the Röpcke Zweers local Hospital (centre 1) we distributed the questionnaire among all nurses in the hospital. As a consequence, most of the nurses in our cohort were working at Cardiac Surgery and Pulmonary Medicine, together almost half of the responding nurses.

Table 1. Response rate and demographics.

\begin{tabular}{lcccc}
\hline & Centre one & Centre two & Centre three & All three \\
\hline Response rate: frequency (\%) & $98 / 160(61.3)$ & $109 / 153(71.3)$ & $43 / 55(78.2)$ & $250 / 368(67.9)$ \\
Female gender: frequency (\%) & $87(88.9)$ & $96(88.1)$ & $32(74.4)$ & $215(86.0)$ \\
Age in years: median (1st Q, 3rd Q) & $35(27,50)$ & $29(24,42)$ & $26(24,39.75)$ & $31(25,43)$ \\
Education level frequency (\%) & & & \\
Intermediate vocational training & $60(61.2)$ & $67(61.4)$ & $17(39.5)$ & $144(57.6)$ \\
Higher vocational training (bach. degr.) & $37(37.8)$ & $41(37.6)$ & $23(53.5)$ & $101(40.4)$ \\
Master degree & $1(1.0)$ & $1(1.0)$ & $0(0)$ & $2(0.8)$ \\
Missing & $0(0)$ & $0(0)$ & $3(7.0)$ & $3(1.2)$ \\
Part-time rate: median \% (1st Q\%, 3rd Q\%) & $67(60,89)$ & $89(78,100)$ & $90(89,90)$ & $89(65,100)$ \\
Experience in years: median (1st Q, 3rd Q) & $8.8(2.6,16.5)$ & $3.0(1.3,7.2)$ & $3.41(1.4,9.0)$ & $4.13(1.6,10.9)$ \\
\hline
\end{tabular}

Respons per practice setting

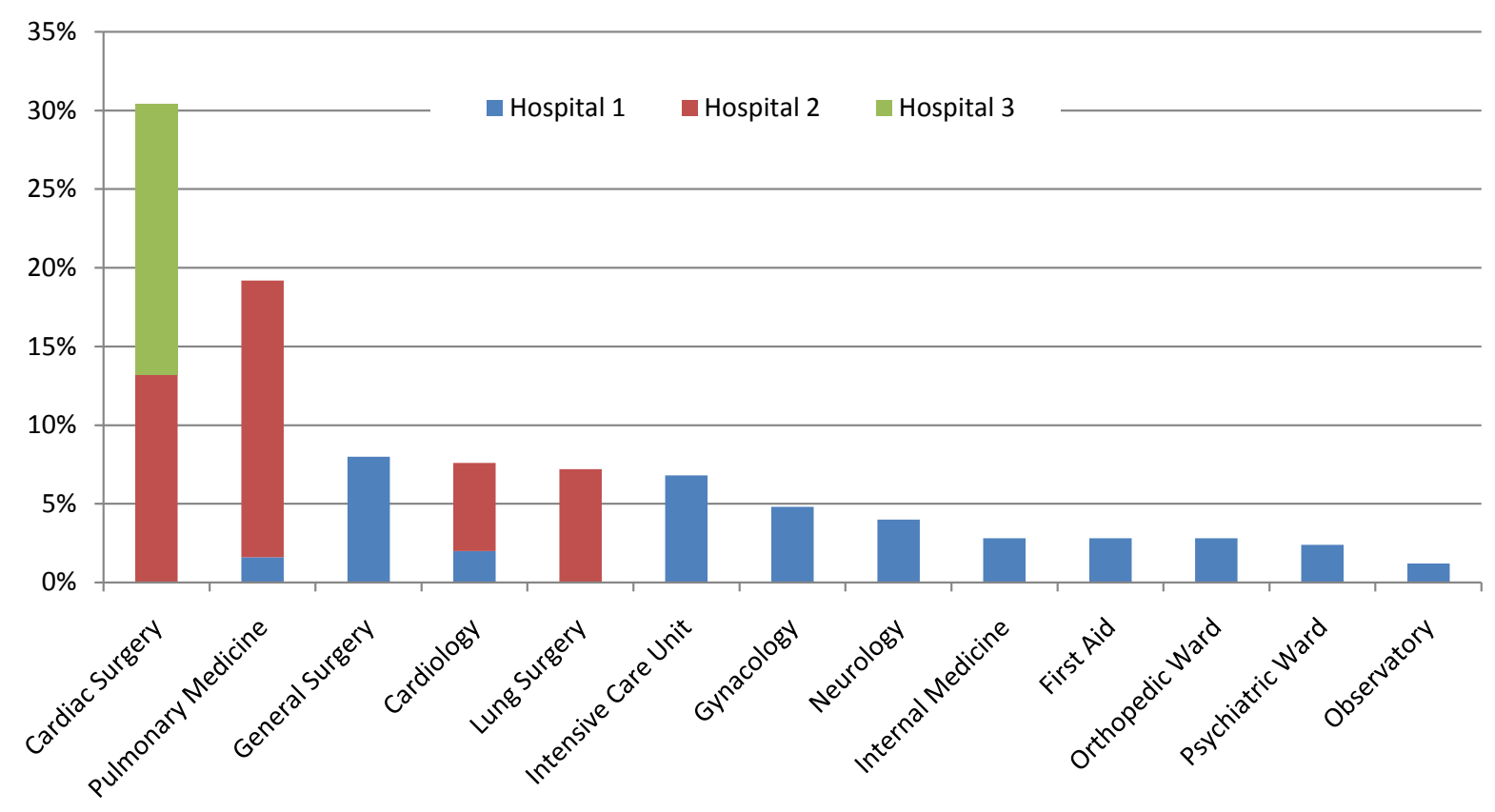

Figure 1. Respons per practice setting. 
The preceding year, $16.4 \%$ of the nurses reported that they attended a workshop or lecture focussed on delirium care and one third read a scientific article about delirium.

\subsection{Nurses Beliefs on the Prevalence of Delirium}

In contrast with the incidences we found in the literature [8]-[13] more than half of the nurses thought that not even $10 \%$ of the patients experienced delirium at their practice setting and $37 \%$ thought that $10 \%-25 \%$ of the patients experienced delirium at their practice setting. In centre one, where nurses from all departments where involved, the lowest prevalence of delirium was estimated by nurses of the emergency department, gynaecology and lung surgery.

\subsection{Nurses' Beliefs on Severity of the Incidence of Delirium and Its Association with Increased Morbidity and Mortality in Older Patients Admitted to the Hospital}

Over $80 \%$ of the nurses thought that delirium is a problem or even a severe problem at their practice setting (Figure 2). They also found especially in older patients, that delirium contributes significantly negative in patients' clinical outcome. The believes of nurses in all three centres were significantly different between patients of 70 years and younger and patients above 70 year of age (Figure 3 ).

\section{Nurses Opinion of Prevention and Treatment of Delirium}

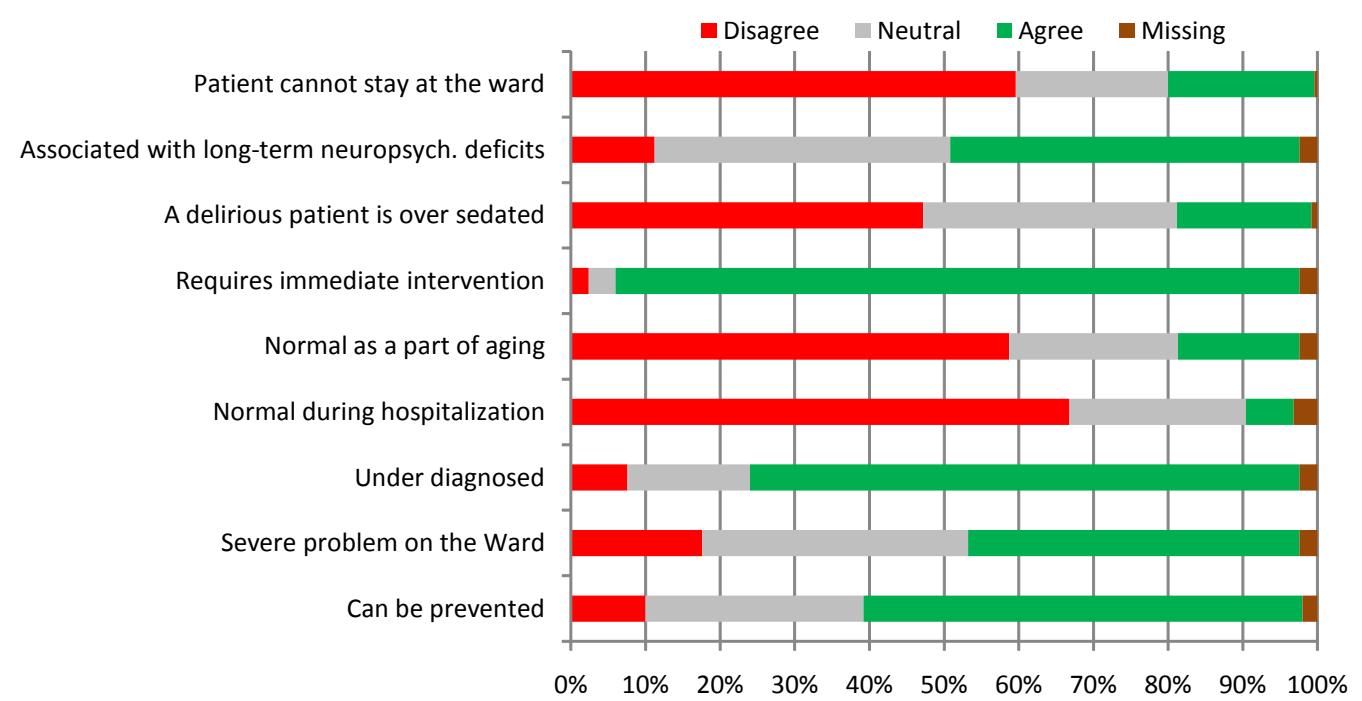

Figure 2. Opinions of prevention and treatment of delirium in patients.

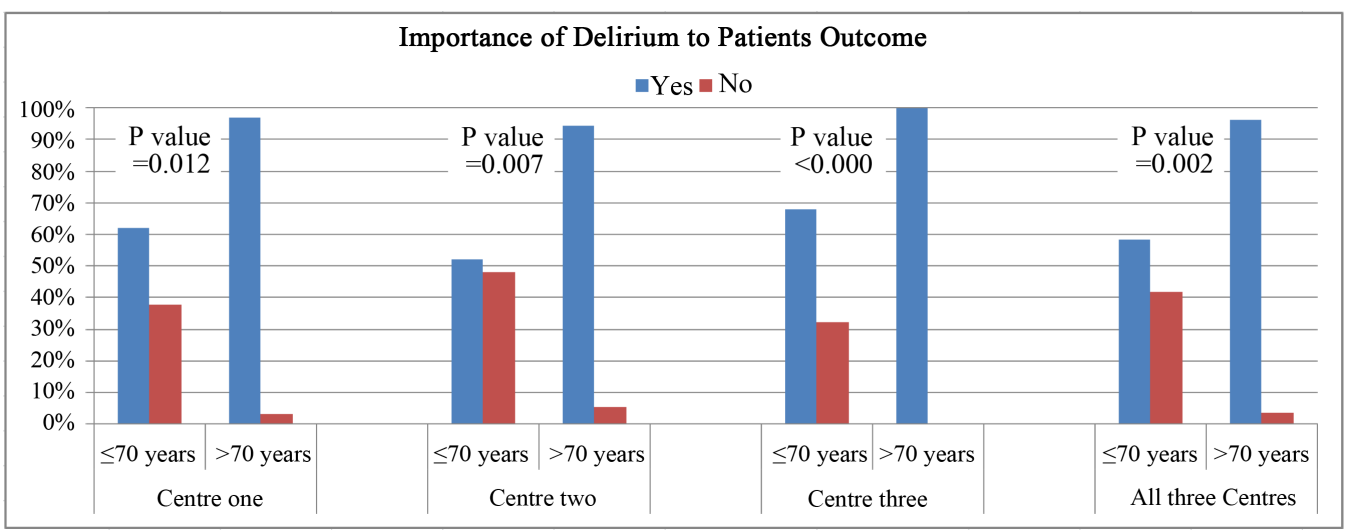

Figure 3. Percentage of healthcare professionals who consider delirium important in the outcome in patients of 70 years or younger versus older than 70 years. 
The most reported serious complications in patients experiencing a delirium are falls, restlessness, confusion, anxiety, panic, heavy feelings of shame and removal of the tubes, due to confusion. Furthermore, the most mentioned unpleasant experiences with delirious patients were aggressive language, being beaten and feeling helpless.

\subsection{Nurses Beliefs on Preventing Delirium}

Delirium can be prevented and the occurrence of delirium at hospital stay should not be found to be normal, that is the opinion of $60 \%$ of all nurses. Almost all nurses (93.9\%) believed that the occurrence of delirium requires an active and immediate intervention by a medical doctor or nurse (Figure 2).

The most important risk factors for the occurrence of Delirium estimated by nurses are medication stop or alcohol or drugs, postoperative status, older age, dementia and infection (Figure 4).

\subsection{Beliefs on Diagnosing Delirium}

Delirium is under diagnosed according to $75 \%$ of the nurses (Figure 2). Nurses are not screening routine based on delirium is said by $63 \%$. Although, we found some variance in screening habits between the three centres, the differences were not significant (Figure 5). Only 9\% of the nurses reported screening patients for delirium on a

\section{Perceived Risk Factors for Delirium}

Quitting medication, alcohol or drugs

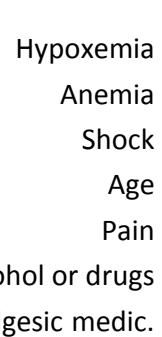

Administr. of sedative/analgesic medic.

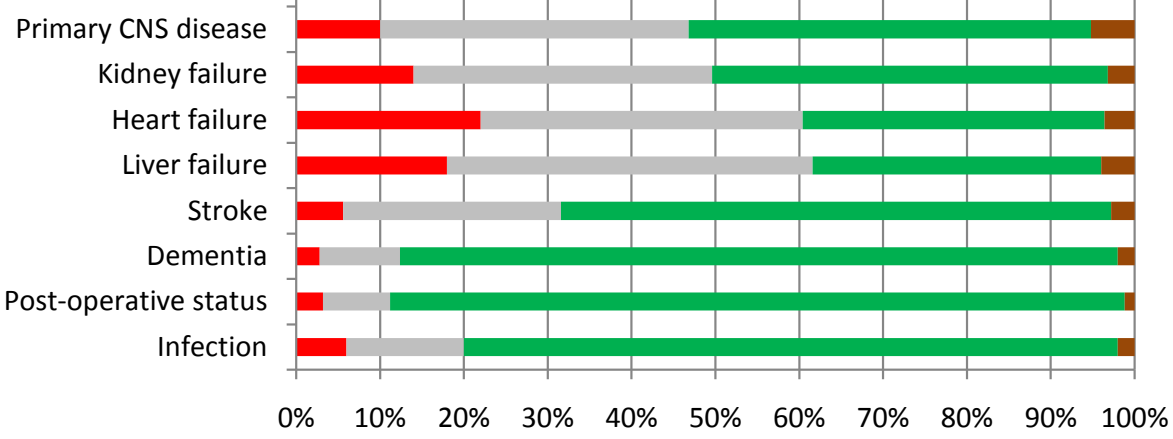

Figure 4. Perceived risk factors which can give rise to delirium.

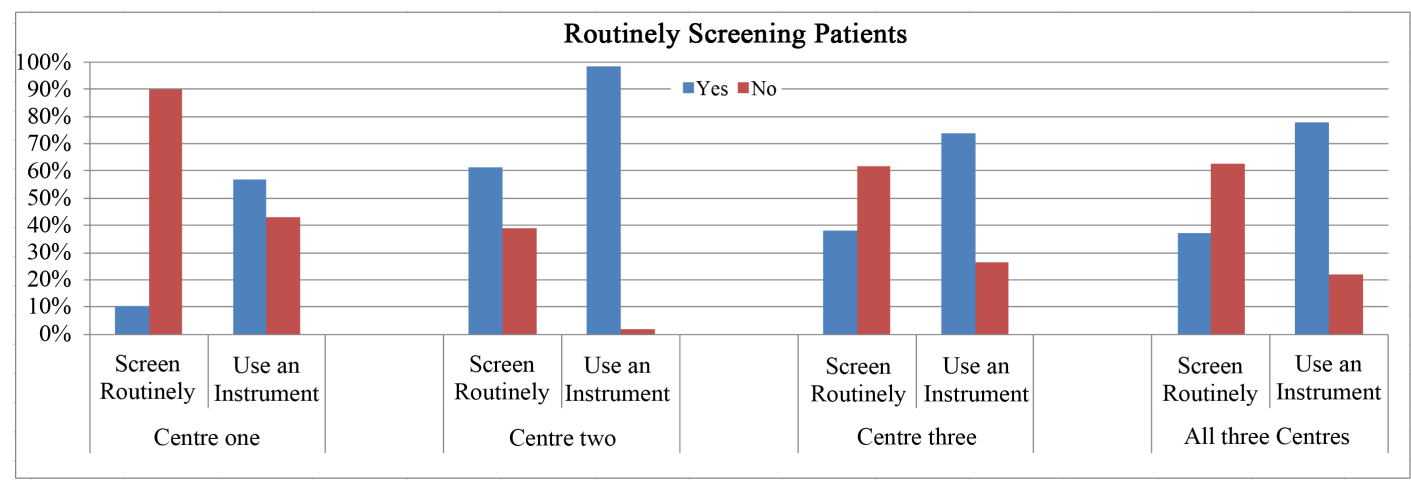

Figure 5. Habits of nurses on routinely screening patients on delirium. 
daily basis. The Delirium Observation Screening (DOS) Scale is the most used screening instrument. Of the nurses who answered the questions about screening instruments, $72 \%$ uses the DOS. Almost $32 \%$ did not answer this question.

In all three centres a delirium guideline or protocol is present. These guidelines include information concerning symptoms, screening and interventions. The presence of a delirium guideline is known by almost $70 \%$ of the nurses, however $60 \%$ of the nurses have never consulted the guideline.

One third of the nurses ask advise from an expert healthcare professional when a patient has been identified with symptoms of delirium.

\subsection{Nurses Beliefs on Treating Delirium}

The occurrence of delirium requires an active and immediate intervention by a medical doctor or a nurse. Medication and intervening in environmental factors, such as reality orientation, are found to be the most important intervention by nurses (Figure 6). The most administered medication is Haldol according to nurses (mentioned by $91 \%$ ), Lorazepam (almost 52\%), Serequel (almost 22\%) and Oxazepam (11\%). The most reported adverse reaction was severe drowsiness in which the patient is no longer approachable, due to over sedation (reported by $54 \%$ of the nurses).

\section{Discussion}

In this study we identified opinions and beliefs on prevention, diagnosis and treatment of delirium of nurses in hospitals working with older hospital patients in general, and specifically in nurses giving care to older cardiac surgery patients in hospitals. We found no differences in knowledge of nurses working with cardiothoracic surgery patients and those working with other adult hospital patients. Nurses do have certain knowledge on prevention, diagnosis and treatment of delirium. Nonetheless, there is a gap between the reported incidence of delirium in literature and the estimation of the occurrence of delirium by nurses. They do not all screen patients on a routinely basis for delirium. Furthermore, a part of the nurses knows that there is a guideline regarding delirium care in their hospital, but most nurses do not consult it. This is an important barrier for policymakers, and clinicians in their efforts to prevent older patients from acquiring a delirium during their hospital stay.

This is the first study giving insight in opinions of nurses in a multi-centre setting since Ely and colleagues in 2004 [22] published their findings on opinions in intensive care caregivers and Verstraete and colleagues in physicians and nurses in 2008 [20]. This preliminary work adds to that body of knowledge, demonstrating that nurses not noticing the degree of risk on delirium in older patients in a hospital, is a barrier for preventing these older patients from acquiring a delirium in a hospital.

To appreciate the present results, a few limiting points must be considered. First, in this study we were not able to collect the real incidence of delirium of the involved patients in the three centres. Of course this would have been the best starting point for comparing the opinions of the nurses on what percentage of patients was delirious in their department and the incidence of delirium. However, in many studies the incidence of delirium in patients admitted to a hospital is reported [6]-[13] [23]-[29], providing a reasonable reference for the incidence.

\section{Opinions of three types of therapy in treating patients}

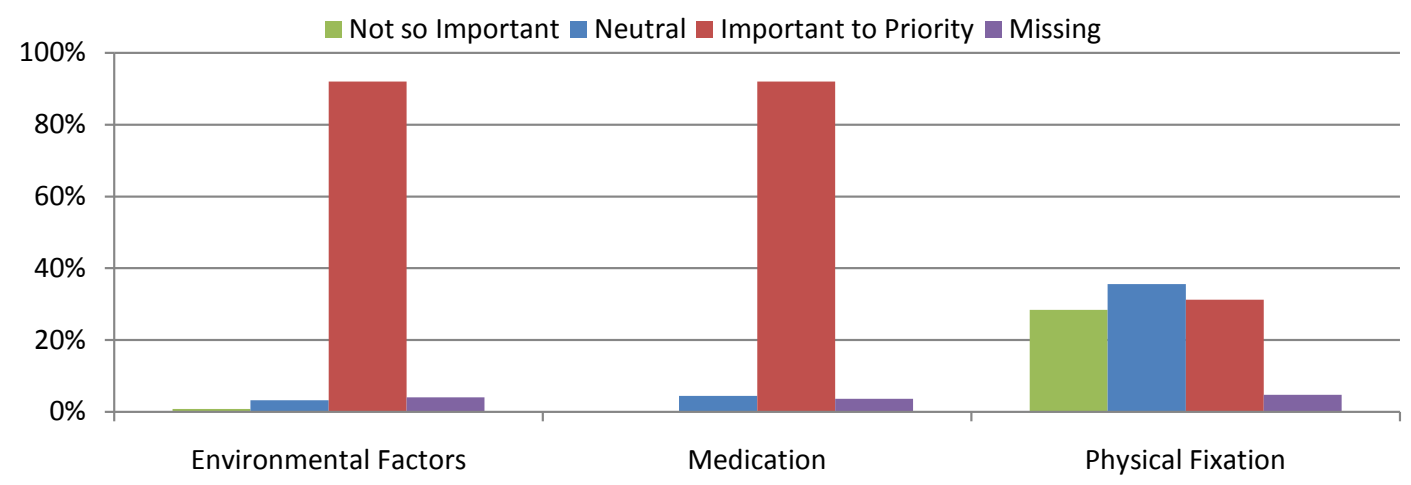

Figure 6. Opinions of nurses on three types of therapy in treating patients with delirium. 
Second, we deliberately compared three different hospital situations including a local hospital with most adult wards, a specific top clinical cardiothoracic surgery department and a cardiac surgery department of a university hospital. On one hand, one can argue this is heterogeneous population. On the other hand we did not find significant differences, meaning that on the level of opinions on delirium care this study population is fairly homogeneous. With our approach, we could reach different hospital nursing populations in order to study their opinions on delirium care.

Finally, this study covers opinions of nurses only and there are no straight directions for implementation studied, as was done by Yevchak and colleagues [30]. However, especially in cardiac surgery there is a remark to make. Most cardiac surgery departments work with so called "clinical pathways". Screening patients on the risk to acquire a delirium on a routine basis could be part of the clinical pathways.

\section{Conclusion}

Although nurses in the hospitals do have knowledge on prevention, diagnosis and treatment of delirium, they underestimate the occurrence of delirium in patients. As a consequence, they do not screen patients on a routine basis. And because they do not screen patients on a routine basis they underestimate the incidence of delirium in older patients during their hospital admission.

\section{Acknowledgements}

We gratefully acknowledge the financial support provided by the Netherlands ministry of Education, Culture and Science managed by the Foundation Innovation Alliance (SIA-RAAK-Publiek, PREDOS 2010-11-13P).

\section{Conflicts of Interest}

None declared.

\section{Financial Support}

We gratefully acknowledge the financial support provided by the Netherlands ministry of Education, Culture and Science managed by the Foundation Innovation Alliance (SIA-RAAK-Publiek, PREDOS 2010-11-13P).

\section{References}

[1] Northrup, W.F., Emery, R.W., Nicoloff, D.M., Lillehei, T.J., Holter, A.R. and Blake, D.P. (2004) Opposite Trends in Coronary Artery and Valve Surgery in a Large Multisurgeon Practice, 1979-1999. Annals of Thoracic Surgery, 77, 488-495. http://dx.doi.org/10.1016/S0003-4975(03)01359-6

[2] Ghotkar, S.V., Grayson, A.D., Fabri, B.M., Dihmis, W.C. and Pullan, D.M. (2006) Preoperative Calculation of Risk for Prolonged Intensive Care Unit Stay Following Coronary Artery Bypass Grafting. European Journal of Cardio-Thoracic Surgery, 31, 1-14.

[3] Litovski, D.S., Dacey, L.J., Baribeau, Y.R., Leavitt, B.J., Clough, R., Cochran, R.P., Quinn, R., Sisto, D.A., Charlesworth, D.C., Malenka, D.J., MacKenzie, T.A., Olmstead, E.M., Ross, C.S. and O’Connor, G.T. (2008) Long-Term Survival of the Very Elderly Undergoing Coronary Artery Bypass Grafting. Annals of Thoracic Surgery, 85, 12331237. http://dx.doi.org/10.1016/j.athoracsur.2007.12.066

[4] Pätilä, T., Kukkonen, S., Vento, A., Pettilä, V. and Suojaranta-Ylinen, R. (2006) Relation of the Sequential Organ Failure Assessment Score to Morbidity and Mortality after Cardiac Surgery. Annals of Thoracic Surgery, 82, 20722079. http://dx.doi.org/10.1016/j.athoracsur.2006.06.025

[5] Stoica, S.C., Sharples, L.D., Ahmed, I., Roques, F., Large, S.R. and Nashef, S.A.M. (2002) Preoperative Risk Prediction and Intraoperative Events in Cardiac Surgery. European Journal of Cardio-Thoracic Surgery, 21, 41-46. http://dx.doi.org/10.1016/S1010-7940(01)01077-6

[6] Martin, B.J., Buth, K.J., Arora, R.C. and Baskett, R.J. (2010) Delirium as a Predictor of Sepsis in Post-Coronary Artery Bypass Grafting Patients: A Retrospective Cohort Study. Critical Care, 14, R171. http://dx.doi.org/10.1186/cc9273

[7] Burkhart, C.S., Dell-Kuster, S., Gamberini, M., Moeckli, A., Grapow, M., Filipovic, M., Seeberger, M.D., Monsch, A.U., Strebel, S.P. and Steiner, L.A. (2010) Modifiable and Nonmodifiable Risk Factors for Postoperative Delirium after Cardiac Surgery with Cardiopulmonary Bypass. Journal of Cardiothoracic and Vascular Anesthesia, 24, 555559. http://dx.doi.org/10.1053/j.jvca.2010.01.003 
[8] Katznelson, R., Djaiani, G., Tait, G., Wasowicz, M., Sutherland, A.M., Styra, R., Lee, C. and Beattie, W.S. (2010) Hospital Administrative Database Underestimates Delirium Rate after Cardiac Surgery. Canadian Journal of Anesthesia, 57, 898-902. http://dx.doi.org/10.1007/s12630-010-9355-8

[9] Kazmierski, J., Kowman, M., Banach, M., Fendler, W., Okonski, P., Banys, A., Jaszewski, R., Rysz, J., Mikhailidis, D.P., Sobow, T. and Kloszewska, I. (2010) Incidence and Predictors of Delirium after Cardiac Surgery: Results from The IPDACS Study. Journal of Psychosomatic Research, 69, 179-185. http://dx.doi.org/10.1016/j.jpsychores.2010.02.009

[10] Smulter, N., Lingehall, H.C., Gustafson, Y., Olofsson, B. and Engström, K.G. (2013) Delirium after Cardiac Surgery: Incidence and Risk Factors. Interactive Cardiovascular and Thoracic Surgery, 17, 790-796. http://dx.doi.org/10.1093/icvts/ivt323

[11] Rudolph, J.L., Inouye, S.K., Jones, R.N., Yang, F.M., Fong, T.G., Levkoff, S.E. and Marcantonio, E.R. (2010) Delirium: An Independent Predictor of Functional Decline after Cardiac Surgery. Journal of the American Geriatrics Society, 58, 643-649. http://dx.doi.org/10.1111/j.1532-5415.2010.02762.x

[12] Saczynski, J.S., Marcantonio, E.R., Quach, L., Fong, T.G., Gross, A., Inouye, S.K. and Jones, R.N. (2012) Cognitive Trajectories after Postoperative Delirium. New England Journal of Medicine, 367, 30-39. http://dx.doi.org/10.1056/NEJMoa1112923

[13] Arenson, B.G., Macdonald, L.A., Grocott, H.P., Hiebert, B.M. and Arora, R.C. (2013) Effect of Intensive Care Unit Environment on In-Hospital Delirium after Cardiac Surgery. The Journal of Thoracic and Cardiovascular Surgery, 146, 172-178. http://dx.doi.org/10.1016/j.jtcvs.2012.12.042

[14] American Psychiatric Association (2000) Diagnostic and Statistical Manual of Mental Disorders. 4th Edition, APA, Washington DC.

[15] Hafner, M. and Singler, K. (2010) Definition and Epidemiology of Delirium in the Elderly. Therapeutische Umschau, 67, 57-61. http://dx.doi.org/10.1024/0040-5930/a000011

[16] Lipowski, Z.J. (1992) Update on Delirium. Psychiatric Clinics of North America, 15, 335-346.

[17] Hudetz, J.A., Patterson, K.M., Byrne, A.J., Pagel, P.S. and Warltier, D.C. (2009) Postoperative Delirium Is Associated with Postoperative Cognitive Dysfunction at One Week after Cardiac Surgery with Cardiopulmonary Bypass. Psychological Reports, 105, 921-932. http://dx.doi.org/10.2466/PR0.105.3.921-932

[18] Schuurmans, M.J., Duursma, S.A. and Shortridge-Baggett, L.M. (2001) Early Recognition of Delirium: Review of the Literature. Journal of Clinical Nursing, 10, 721-729. http://dx.doi.org/10.1046/j.1365-2702.2001.00548.x

[19] McCusker, J., Cole, M., Abrahamowicz, M., Primeau, F. and Belzile, E. (2002) Delirium Predicts 12-Month Mortality. Archives of Internal Medicine, 162, 457-463. http://dx.doi.org/10.1001/archinte.162.4.457

[20] Verstraete, L., Joosten, E. and Milisen, K. (2008) Opinions of Physicians and Nurses Regarding the Prevention, Diagnosis and Management of Delirium. Tijdschrift voor Gerontologie en Geriatrie, 39, 26-34. http://dx.doi.org/10.1007/BF03078120

[21] Inspectie voor de Gezondheidszorg (2005) De oudere patient met een delirium in het ziekenhuis: Verwardheid nog onvoldoende onderkent. IGZ, Den Haag, 5-51. https://zoek.officielebekendmakingen.nl/kst-30300-XVI-23-b1.pdf

[22] Ely, E.W., Stephens, R.K., Jackson, J.C., Thomason, J.W., Truman, B., Gordon, S., et al. (2004) Current Opinions Regarding the Importance, Diagnosis, and Management of Delirium in the Intensive Care Unit: A Survey of 912 Healthcare Professionals. Critical Care Medicine, 32, 106-112. http://dx.doi.org/10.1097/01.CCM.0000098033.94737.84

[23] Schuurmans, M.J., Duursma, S.A., Shortridge-Baggett, L.M., Clevers, G.J. and Pel-Little, R. (2003) Elderly Patients with a Hip Fracture: The Risk for Delirium. Applied Nursing Research, 16, 75-84. http://dx.doi.org/10.1016/S0897-1897(03)00012-0

[24] Koster, S., Hensens, A.G., Schuurmans, M.J. and van der Palen, J. (2010) Risk Factors of Delirium after Cardiac Surgery: A Systematic Review. European Journal of Cardiovascular Nursing, 10, 197-204.

http://cnu.sagepub.com/content/10/4/197.full.pdf+html http://core.kmi.open.ac.uk/download/pdf/11481402.pdf\#page=33

[25] Rathier, M.O. and Baker, W.L. (2011) A Review of Recent Clinical Trials and Guidelines on the Prevention and Management of Delirium in Hospitalized Older Patients. Hospital Practice, 39, 96-106. http://dx.doi.org/10.3810/hp.2011.10.928

[26] Norkienė, I., Ringaitienė, D., Kuzminskaitè, V. and Šipylaitė, J. (2013) Incidence and Risk Factors of Early Delirium after Cardiac Surgery. BioMed Research International, 2013, 1-5. http://dx.doi.org/10.1155/2013/323491

[27] Bakker, F.C., Persoon, A., Bredie, S.J., van Haren-Willems, J., Leferink, V.J., Noyez, L., Schoon, Y. and Olde Rikkert, M.G. (2014) The CareWell in Hospital Program to Improve the Quality of Care for Frail Elderly Inpatients: Results of a Before-After Study with Particular Focus on Surgical Patients. The American Journal of Surgery, 208, 735-746. 
http://dx.doi.org/10.1016/j.amjsurg.2014.04.009

[28] Radinovic, K.S., Markovic-Denic, L., Dubljanin-Raspopovic, E., Marinkovic, J., Jovanovic, L.B. and Bumbasirevic, V. (2014) Effect of the Overlap Syndrome of Depressive Symptoms and Delirium on Outcomes in Elderly Adults with Hip Fracture: A Prospective Cohort Study. Journal of the American Geriatrics Society, 62, 1640-1648. http://dx.doi.org/10.1111/jgs.12992

[29] de Castro, S.M.M., Ünlü, Ç., Tuynman, J.B., Honig, A., van Wagensveld, B.A., Steller, E.P. and Vrouenraets, B.C. (2014) Incidence and Risk Factors of Delirium in the Elderly General Surgical Patient. The American Journal of Surgery, 208, 26-32. http://dx.doi.org/10.1016/j.amjsurg.2013.12.029

[30] Yevchak, A.M., Fick, D.M., McDowell, J., Monroe, T., May, K., Grove, L., Kolanowski, A.M., Waller, J.L. and Inouye, S.K. (2014) Barriers and Facilitators to Implementing Delirium Rounds in a Clinical Trial across Three Diverse Hospital Settings. Clinical Nursing Research, 23, 201-215. http://dx.doi.org/10.1177/1054773813505321 


\section{Appendix. Questionnaire “Opinions of Nurses Regarding Prevention, Diagnosis and Treatment of Delirium in Older Hospital Patients"}

\section{Part I: General Information}

What is your age? years

\section{What is your gender?}

$\square$ Female

$\square \quad$ Male

What is your highest completed education?

$\square \quad$ Intermediate vocational in nursing (including in-service-training)

$\square \quad$ Higher vocational in nursing (bachelor degree)

$\square \quad$ Master degree in nursing

On what (part of) department do you work the most? (Choose one)

$\square \quad$ Cardiac surgery

$\square \quad$ Lung surgery

$\square \quad$ Internal medicine

$\square \quad$ Cardiology

$\square \quad$ Neurology

$\square \quad$ Pulmonary medicine

$\square \quad$ Intensive care

$\square \quad$ Medium care

$\square \quad$ Emergency

$\square$ Observatory

口 Psychiatric ward

$\square \quad$ Recovery

口 General surgery

$\square \quad$ Orthopaedic ward

口 Gynaecology

$\square$ Other:

How much do you work now?

口 Full $=100 \%$

$\square$ Part-time: $\%$

How many years of experience do you have in your current employment? years months

How many years did you work as a nurse since you've graduated? years months

\section{PART II: Beliefs about Delirium}

\section{Definition of "Delirium"}

It is a psychic syndrome, as a result of a physical disorder, which is characterized by a clouding of consciousness with reduced attention and by a disturbance in cognition (e.g., disorientation, memory disorders) or perception (e.g. hallucinations). The symptoms develop in a few hours up to days and can fluctuate during the course of the day (APA, 1994).

\section{Approximately what percentage of patients is delirious in your department?}

\begin{tabular}{cccccc}
\hline$\square$ & $\square$ & $\square$ & $\square$ & $\square$ \\
Under $10 \%$ & $10 \%-25 \%$ & $26 \%-50 \%$ & $51 \%-75 \%$ & $76 \%-100 \%$ & $\square$ \\
\hline
\end{tabular}

2. To what extent do you think delirium is a problem in your department? (Please tick what best reflects your opinion)

\begin{tabular}{ccccc}
\hline$\square$ & $\square$ & $\square$ & $\square$ & $\square$ \\
No problem & Small problem & Problem & Serious problem & Significant problem \\
\hline
\end{tabular}


3. Does a delirium influence the prognosis of:

(Please tick what best reflects your opinion)

a. adult patients (16 - 70 years)

$\begin{array}{ll}\square & \square \\ \text { Yes } & \text { No }\end{array}$

b. older patients (above 70 years)

$\begin{array}{ll}\square & \square \\ \text { Yes } & \text { No }\end{array}$

4. To what extent do you agree with the following statements?

(Please tick what best reflects your opinion)

\begin{tabular}{lcccc}
\hline & $\begin{array}{c}\text { Strongly } \\
\text { disagree }\end{array}$ & & $\begin{array}{c}\text { Totally } \\
\text { agree }\end{array}$ \\
\hline Prevention of delirium is possible & $\square$ & $\square$ & $\square$ & $\square$ \\
Delirium is an under diagnosed syndrome & $\square$ & $\square$ & $\square$ \\
Delirium does commonly occurrence in the hospital & $\square$ & $\square$ & $\square$ & $\square$ \\
Delirium is a normal phenomenon in the aging process & $\square$ & $\square$ & $\square$ & $\square$ \\
Delirium is a problem that requires an immediate and & $\square$ & $\square$ & $\square$ & $\square$ \\
active intervention of the doctor and nurse & $\square$ & $\square$ & $\square$ \\
Patients with a delirium are over sedated & $\square$ & $\square$ & $\square$ \\
Long-term neuropsychological disorders may result from delirium & $\square$ & $\square$ & $\square$ \\
A patient with delirium may not stay admitted to our department & $\square$ & $\square$ & $\square$ & $\square$
\end{tabular}

5. In your experience, which of the following risk factors give rise to delirium?

(Rate in function of importance by circling the number that best reflects your opinion on the following scale: 1 represent "not important" and 5 represent "very important".)

\begin{tabular}{|c|c|c|c|c|c|}
\hline & $\begin{array}{c}\text { Not } \\
\text { important }\end{array}$ & & & & $\begin{array}{c}\text { Very } \\
\text { important }\end{array}$ \\
\hline Infection & 1 & 2 & 3 & 4 & 5 \\
\hline Post-operative condition & 1 & 2 & 3 & 4 & 5 \\
\hline Dementia & 1 & 2 & 3 & 4 & 5 \\
\hline Ischemic brain diseases (stroke, bleeding) & 1 & 2 & 3 & 4 & 5 \\
\hline Liver failure & 1 & 2 & 3 & 4 & 5 \\
\hline Heart failure & 1 & 2 & 3 & 4 & 5 \\
\hline Kidney failure & 1 & 2 & 3 & 4 & 5 \\
\hline Disease of the central nervous system & 1 & 2 & 3 & 4 & 5 \\
\hline Administering sedative/analgesic medications & 1 & 2 & 3 & 4 & 5 \\
\hline Discontinuation of medication, alcohol or drugs & 1 & 2 & 3 & 4 & 5 \\
\hline Pain & 1 & 2 & 3 & 4 & 5 \\
\hline Age & 1 & 2 & 3 & 4 & 5 \\
\hline Shock & 1 & 2 & 3 & 4 & 5 \\
\hline Anaemia & 1 & 2 & 3 & 4 & 5 \\
\hline Low saturation & 1 & 2 & 3 & 4 & 5 \\
\hline
\end{tabular}

\section{6. a. Does your department routinely screen risk patients on delirium?}

$\begin{array}{ll}\square & \square \\ \text { Yes } & \text { No }\end{array}$

b. When are risk-patients screened for delirium?

\begin{tabular}{ccccc}
\hline$\square$ & $\square$ & $\square$ & $\square$ & $\square$ \\
At admission & Daily & At discharge & Otherwise & Not applicable \\
\hline
\end{tabular}


c. Do you use an instrument for this?

$\square$ Yes

$\square$ No

If so, what instrument:

7. What is the most serious complication that you have experienced at a delirious patient before treatment of delirium was started?

a. For the patient:

b. For you as a caregiver:

8. a. Are you aware of the guideline for delirium care in your hospital information-system? aYes aNo

Have you ever consulted this guideline?

If Yes, do you consider this a usable guideline?

$\begin{array}{ll}\text { aYes } & \text { aNo } \\ \text { aYes } & \text { aNo }\end{array}$

b. How often do ask you additional advice in a delirious patient in your department?

\begin{tabular}{cccc}
\hline$\square$ & $\square$ & $\square$ & $\square$ \\
Never & Seldom & Usually & Always \\
\hline
\end{tabular}

If you seek advice, to which specialism?

9. How important do you think the following therapy is in treating patients with delirium?

(Please tick what best reflects your opinion)

a. Environmental measures (communication, reality orientation, sensory stimuli)

\begin{tabular}{ccccc}
\hline$\square$ & $\square$ & $\square$ & $\square$ & $\square$ \\
Not important & Less important & Neutral & Important & Priority \\
\hline
\end{tabular}

b. Medication

\begin{tabular}{ccccc}
\hline$\square$ & $\square$ & $\square$ & $\square$ & $\square$ \\
Not important & Less important & Neutral & Important & \\
\hline C. Physical fixation & & & & \\
\hline$\square$ & $\square$ & $\square$ & $\square$ & $\square$ \\
Not important & Less important & Neutral & Important & Priority \\
\hline
\end{tabular}

10. a. What medications are prescribed to treat delirium?

$\mathrm{mg}$; $\mathrm{mg}$;

b. What side effects have you ever seen in patients using medication for delirium?

mg Ddo not know

\section{In the last 12 month:}

a. did you attended a training about delirium care?

If not, would you want to follow this training?

b. did you read a scientific article on delirium?

(Excluding the directive in the hospital information)

$\begin{array}{ll}\text { aYes } & \text { aNo } \\ \text { aYes } & \text { aNo }\end{array}$

aYes $\quad \square$ No

\section{Comments:}


Scientific Research Publishing (SCIRP) is one of the largest Open Access journal publishers. It is currently publishing more than 200 open access, online, peer-reviewed journals covering a wide range of academic disciplines. SCIRP serves the worldwide academic communities and contributes to the progress and application of science with its publication.

Other selected journals from SCIRP are listed as below. Submit your manuscript to us via either submit@scirp.org or Online Submission Portal.
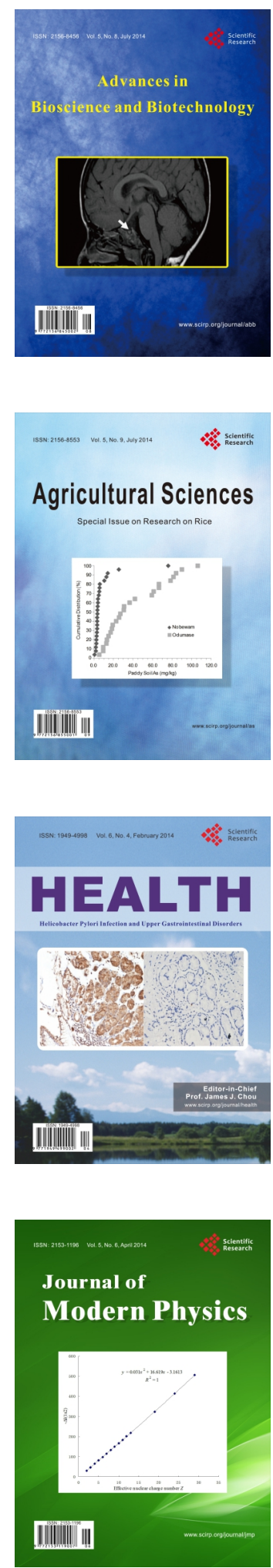
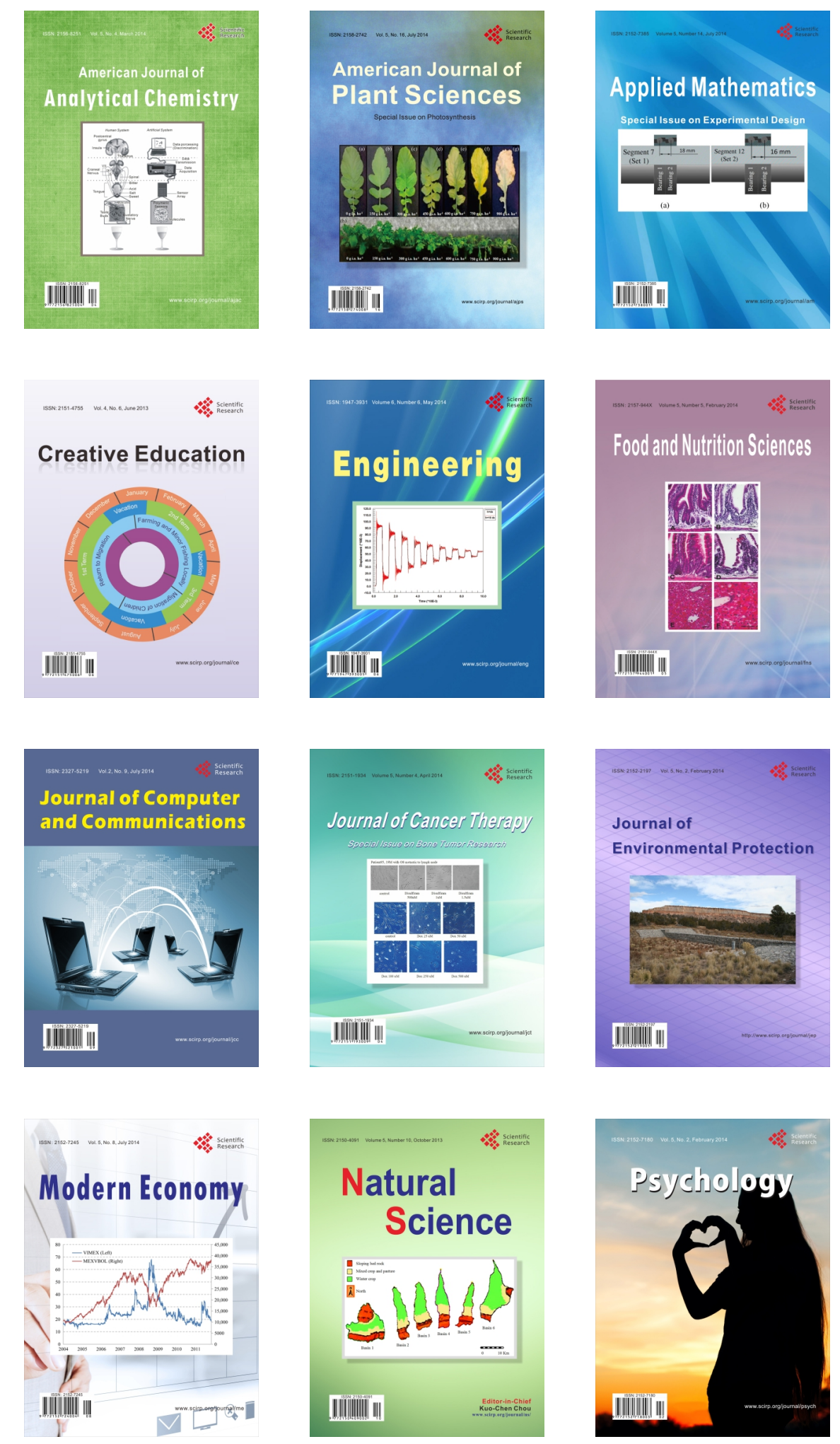